\title{
obituaries
}

columns

\section{Thomas Lynch}

\section{Formerly Professor of Psychiatry, Royal College of Surgeons, Dublin, Eire}

Tom was born in Eire on 10 October 1922, and spoke only Irish until he learned English at school. By his own account his athletic prowess carried him through school with minimum scholastic effort. Useful at rugby, he excelled at golf and bottomed out at a handicap of four. Consistently gaining first place and attendant scholarships at the Royal College of Surgeons Medical School (RCSI), he qualified LRCPI, LM in 1946 with first class honours and with a desire to practise as a physician. Following his intern year and with MRCPI in mind, he accepted Norman Moore's invitation to be an assistant physician at Swift's St Patrick's Hospital, Dublin. Duly gaining MRCPI in 1948, he also passed the DPM and was finally persuaded to pursue a career in psychiatry.

He spent 1952 at the Maudsley Hospital with Felix Post. Returning to Dublin, in 1956 he was appointed staff physician at St Patrick's and visiting consultant to the Meath Hospital in Dublin. In 1961 he became Resident Medical Superintendent at St Otteran's Hospital, Waterford, where he set up the first psychiatric unit in a general hospital in the Republic of Ireland which included contractual responsibilities for the pigs and sheep on the hospital farm!

Now at last, he was running his own show but could not resist when the first professorship of psychiatry was advertised by the Royal College of Surgeons of Ireland. His successful candidacy saw him returning to Dublin in 1968 as Clinical Director and Foundation Professor with his clinical base at St Brendan's Hospital, Grangegorman. In subsequent years he set up a modern community-based

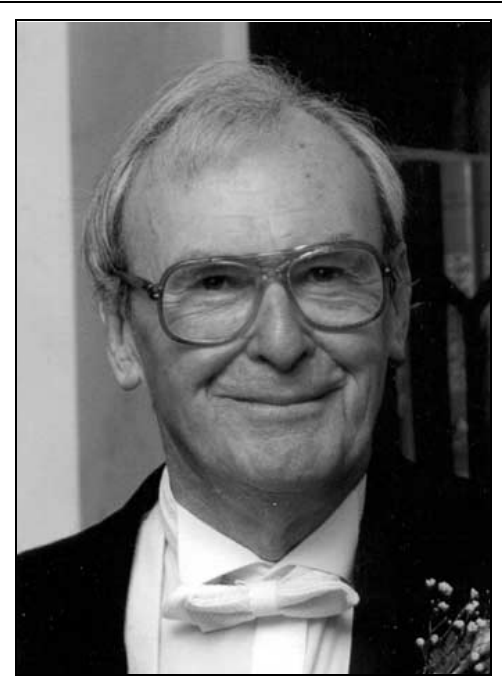

perceived the aspirations of a small number of Irish colleagues towards an Irish National College as premature and unlikely to command wide support: in this he had the support of his professorial colleagues, with whom he formed an Irish National Psychiatric Postgraduate Training Committee even before the new College came into being in 1971.

At home in Ireland, Tom served on a number of important boards, including The National Drugs Advisory Board, The National Rehabilitation Board, the Central Remedial Clinic and the Eastern Health Board. In his professional practice he was dedicated to excellence of care in public service provision, the furtherance of Irish psychiatry and the teaching of his subject to medical students. He belonged to a generation of Irish psychiatrists dedicated to replacing the largest national comple-

service, opened a general hospital unit at James Connolly Memorial Hospital outside Dublin and rapidly developed undergraduate psychiatric teaching at RCSI. In his foreword to his lecture notes he observed that the contribution of psychiatry to the understanding of the principles and practice of medicine must ultimately be to underline the wholeness and dignity of man. He advised students that physicians are always practising psychiatry simply because they are dealing with sick people.

'We are all members of a caring profession, but being human, our motives are mixed and our performance may sometimes be flawed. A dose of personal humility is required as maintenance therapy.'

Tom was a staunch supporter of the Royal College of Psychiatrists without compromising his loyalty to RCPI and his alma mater RCSI. He was elected a Foundation Fellow in 1971 and served as Senior Vice-President (1981-1983) and subsequently on the Court of Electors. He ment of Victorian mental hospitals in the world with modern psychiatric services a task as yet unfinished. He was a foundation member and chairman of the Irish Mental Health Association, which he continued to actively support well into his retirement. While Chairman of the Irish Division he organised a successful joint meeting of the College and the American Psychiatric Association (APA) in Dublin in recognition of which he subsequently was the APA. a Cork medical graduate. The famously hospitable Lynch home was, and is, appropriately sited near Milltown Golf Club in Dublin of which Tom, like his father before him, was captain. On 6 January 2005 Tom died peacefully surrounded by his family after a long period of ill health. All five of his children are leaders of caring professions and with one exception are based in Dublin. There are, to date, ten grandchildren.

T. J. Fahy awarded a Corresponding Fellowship by

In 1956 Tom married Sheila O'Donovan, 